\title{
Publisher Correction: Speed scaling in multiphoton fluorescence microscopy
}

Jianglai Wu(D), Na Ji(D) and Kevin K. Tsia (D)

Correction to: Nature Photonics https://doi.org/10.1038/s41566-021-00881-0, published online 27 October 2021.

In the version of this Review Article initially published online, there was a discrepancy between the data points shown in Fig. 1a and the corresponding color bar. The image has been updated to better represent the correlation of data and colors. The original and corrected Fig. 1a images are shown below.

The changes have been made to the online version of the Review Article.

a

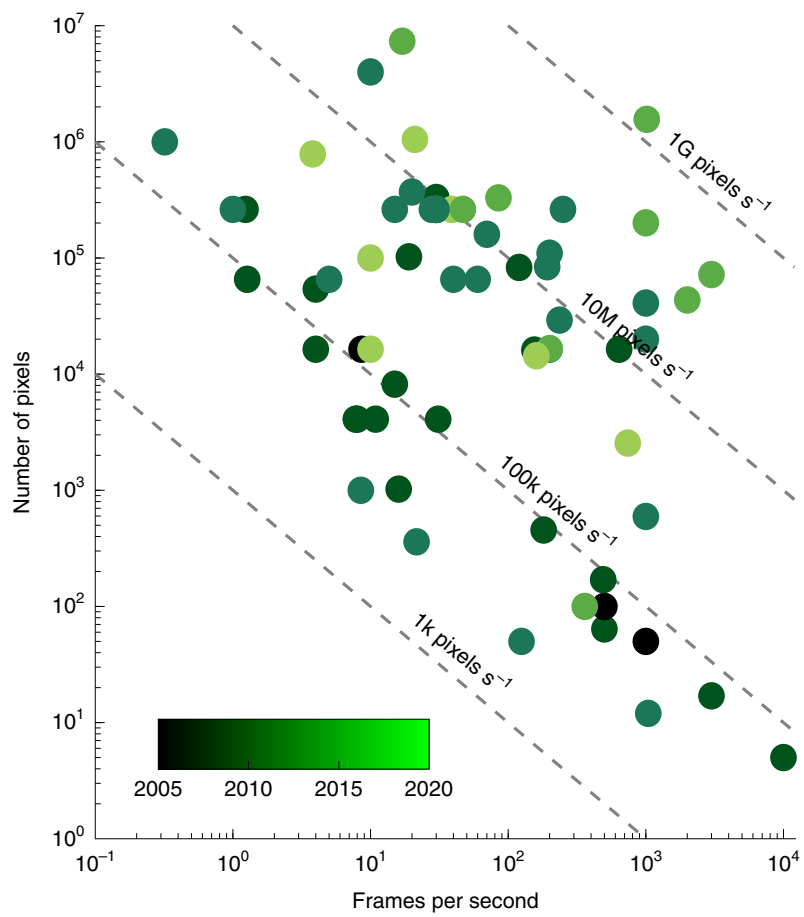

a

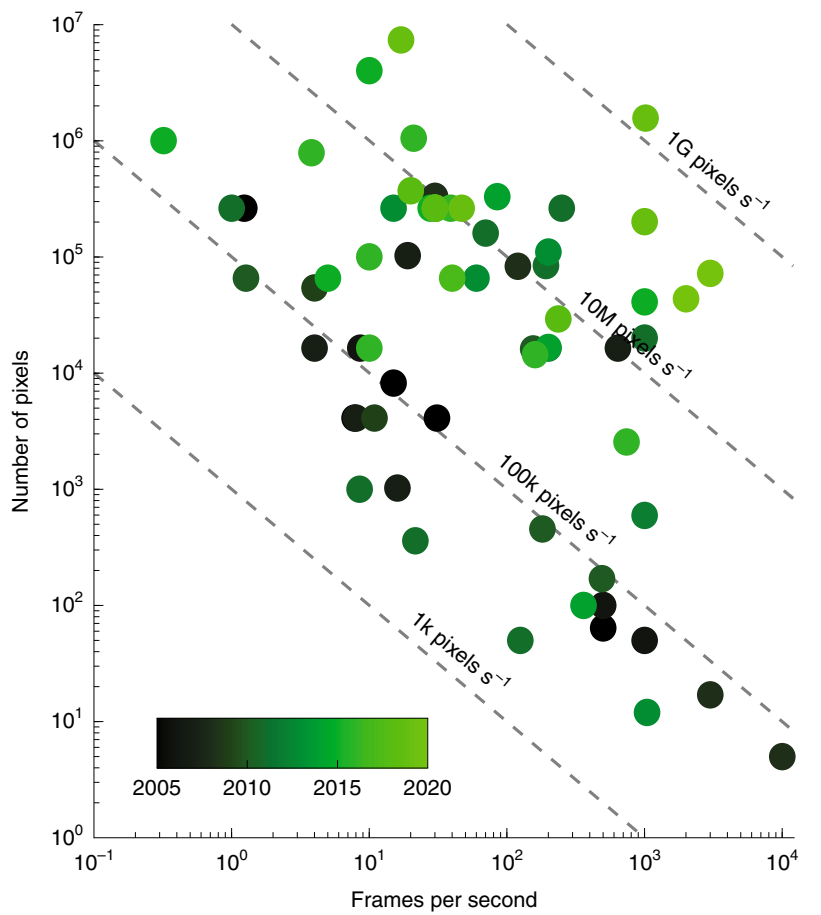

Fig. 1 | Original and Corrected.

Published online: 29 November 2021

https://doi.org/10.1038/s41566-021-00938-0

๑ Springer Nature Limited 2021 